\title{
MINI-CURSO "BIOLOGIA FORENSE: A CIÊNCIA DESVENDANDO O CRIME" - DISCUTINDO TECNOLOGIA E CIÊNCIA EM SALA DE AULA
}

\author{
Yngrid Garay Berriel, Adriane Yumi Babá, Gabrielle Ossucci, Dulcinéia Ester Pagani Gianotto \\ Universidade Estadual de Maringá/DBI. Av. Colombo, n. 5790, Maringá (PR), Cep: 87020-900. E-mail: didyka@hotmail.com
}

\section{RESUMO}

A Biologia Forense é abordada no dia-a-dia em investigações criminais, seriados de TV e é um tema que atrai a curiosidade humana. Com o objetivo de levar aos alunos um tema atual e que comumente não é discutido nas aulas de biologia, surgiu a oportunidade de apresentar um mini-curso sobre Biologia Forense aos alunos do $2^{\circ}$ e $3^{\circ}$ ano do Ensino Médio de um Colégio Estadual de Maringá - PR. Almejando que os alunos compreendessem a importância da formação de peritos especializados nessa área, e como se comportam em uma cena de crime, diversas atividades de caráter educativo foram realizadas com dinâmicas e práticas, levantamento de hipóteses e discussões que, de acordo com os participantes, foram essenciais para a compreensão dos conhecimentos adquiridos durante o mini-curso. As discussões sobre as tecnologias utilizadas nas Ciências Forenses mostraram-se eficientes na construção de conhecimentos relacionados à Biologia e outras áreas abordadas pelo tema.

Palavras - chaves: DNA, crimes, Tecnologia.

\section{SHORT COURSE "FORENSIC BIOLOGY: SCIENCE UNREVEALING CRIME" - DISCUSSING SCIENCE AND TECHNOLOGY INSIDE THE CLASSROOM}

\begin{abstract}
Forensic Biology is applied to criminal investigations every day. Because of its appeal to human curiosity, it has been largely explored by TV series. Aiming to supply the students with an up-to-date subject, uncommonly discussed in Biology classes, an opportunity has emerged of presenting a short course on Forensic Biology to $2^{\text {nd }}$ and $3^{\text {rd }}$ grade students of a High School in Maringá, Brazil. In order to get the students to understand the importance of training experts in this area of knowledge and how the latter behave on a crime scene, various didactics activities have been performed including practices and teamwork, rising of hypothesis and discussions which, according to those attending, were essential on developing the knowledge acquired during the course. The debate on the technologies used by the Forensic Sciences have turn up efficient when building knowledge related to Biology and other areas which have been approached in the course.
\end{abstract}

Keywords: DNA, crimes, technology. 


\section{INTRODUÇÃO}

O mini-curso é uma modalidade de ensino-aprendizagem que proporciona interesse, conhecimento e curiosidade ao abordar assuntos muitas vezes não trabalhados em aula (BIMBATO et al., 2009). Geralmente a escolha de um tema para o mini-curso envolve assuntos atuais que estão sendo discutidos ou são muito polêmicos.

Um dos temas atuais que envolve a Biologia é a Ciência Forense, que pode ser definida como uma ciência multidisciplinar, uma vez que se utiliza muitas vezes de outras ciências para a devida análise de um possível vestígio. Assim como o Juiz recorre a vários elementos para formar sua convicção e aplicar a lei da melhor forma possível, o profissional forense se vale do conhecimento, nos mais diversos ramos da ciência, para melhor análise dos indícios encontrados na cena de um crime (CALAZANS; CALAZANS, 2010).

A Ciência Forense tem se beneficiado da evolução científica da Biologia, Química e Física, através da aplicação das tecnologias derivadas destas áreas do saber. As técnicas utilizadas na resolução de crimes, nos últimos 100 anos, refletem esta evolução. Entre as importantes contribuições destas ciências podem-se citar, por exemplo, a Física na balística, a Química na identificação e caracterização de moléculas químicas e a Biologia na identificação humana com os grupos sanguíneos $A B O, R h$, entre outros (SILVA; PASSOS, 2006).

Devido ao caráter multidisciplinar do exame pericial, são necessários que peritos criminais, médicos e odontologistas associem técnicas periciais tradicionais às análises em Biologia molecular e exames de DNA com o intuito de apresentar resultados mais confiáveis, objetivos e específicos (SILVA et al. apud BARALDI, 2008).

A história recente dos tribunais tem sido marcada por avanços científicos e tecnológicos provenientes tanto das Ciências Forenses como da Informática aplicáveis à administração da justiça (NUNES; MACHADO, 2004). Se a ciência a serviço dos tribunais não é recente, pode-se, no entanto afirmar que nos últimos anos se assistiu uma reconfiguração marcante desse fenômeno. Enquanto exemplo de ciência aplicada por excelência, as Ciências Forenses caracterizam-se pela diversidade dos seus domínios de conhecimentos e de aplicação no meio judicial, de que resultam diferentes usos e representações na mobilização da prova pericial da parte dos atores judiciários (NUNES; MACHADO, 2004).

Nos dias de hoje, a utilização do DNA em nível da administração da justiça concretiza-se, essencialmente, em três situações distintas: para identificação de suspeitos e de vítimas de crimes e no âmbito da investigação de paternidade e de maternidade (OLIVEIRA, 1999 apud MACHADO, 2004). Ou seja, a Biologia Forense garante a discussão em sala de aula de conhecimentos científicos, que envolvem novas tecnologias e situações que podem ocorrer no cotidiano da sociedade, sendo um tema atual e de fácil contextualização e, através da problematização, pode gerar debates em que os alunos se desenvolvam intelectualmente.

Por envolver mais de uma disciplina, a Ciência Forense caracteriza-se como tema transversal. Segundo Barbosa (2007), os temas transversais são temas destacados da realidade social que, ao serem tratados, produzem encontros importantes entre a disciplina e a vida real. O uso de temas transversais é uma forma de garantir a interdisciplinaridade no ensino/aprendizagem e de possibilitar que o aprendiz torne significativo o que aprende.

Temas atuais, polêmicos, vivenciais, utilizados no processo de ensinar e aprender, trazem para a escola a possibilidade de dar significado às disciplinas ali ensinadas, ou seja, ampliar a visão e instrumentar o aprendiz, para 
que a disciplina escolar tenha uma função social (BARBOSA, 2007).

A importância de discutir com os alunos os avanços da ciência e tecnologia, suas causas, conseqüências, os interesses econômicos e políticos, de forma contextualizada, está no fato de que devemos conceber a ciência como fruto da criação humana. É preciso que o Ensino Médio dê ao aluno condições de compreender a natureza do contexto científico-tecnológico e seu papel na sociedade. Isso implica adquirir conhecimentos básicos sobre filosofia e história da ciência, para estar a par das potencialidades e limitações do conhecimento científico (PINHEIRO, 2007).

A Biologia Forense, sendo uma das áreas da Ciência Forense, utiliza os conhecimentos e as técnicas de Genética e de Biologia Molecular, para apoiar e auxiliar a justiça a solucionar casos sob investigação policial e/ou do Ministério Público, ou simplesmente na identificação de pessoas. Este tema foi escolhido para ser ministrado a alunos do Ensino Médio, a fim de proporcionar-Ihes conhecimentos de outras áreas aos quais a disciplina de Biologia está envolvida, atualizando-os sobre esta nova área de atuação do biólogo e também proporcionando a oportunidade de aprendizagem a partir de situações diferenciadas.

\section{OBJETIVO}

Este artigo tem como objetivo analisar as contribuições que o mini-curso "Biologia Forense, a ciência desvendando o crime" proporcionou aos alunos do $2^{\circ}$ e $3^{\circ}$ ano do Ensino Médio do Colégio Estadual Doutor Gastão Vidigal-Maringá/PR.

\section{METODOLOGIA}

Os acadêmicos do $4^{\circ}$ ano do curso de Ciências Biológicas da Universidade Estadual de Maringá e alunos da disciplina de Estágio Supervisionado II desenvolveram, como atividade de Estágio Supervisionado não convencional, o mini-curso - "Biologia Forense: a ciência desvendando o crime".

Este mini-curso foi oferecido para alunos do Ensino Médio de uma escola pública da cidade de Maringá-PR e teve como objetivo abordar um tema atual, de forma dinâmica e interativa, que comumente não é discutido nas aulas de Biologia, a fim de ampliar a visão do aluno de Ensino Médio sobre as diferentes áreas que a Biologia está inserida, sendo a Biologia Forense um dos caminhos que o biólogo pode seguir e, também, demonstrar aos alunos a importância da interdisciplinaridade, a interação dessas áreas com a tecnologia e como são dependentes dos conhecimentos gerados umas pelas outras.

O mini-curso foi realizado nos dias $15 \mathrm{e}$ 16 de junho, com duração de 10 horas/aulas no período noturno, com a participação de 16 alunos do Ensino Médio. Os temas abordados foram as diversas áreas das Ciências Forenses, com enfoque nos seguintes conteúdos: Biologia Forense, breve histórico, preservação e análise de evidências; Anatomia - nomenclatura, estruturas e sistemas do corpo humano; Genética, identificação genética individual ou biológica de parentesco; Citologia - estruturas componentes das células que podem auxiliar a Biologia Forense; Biometria, características físicas ou comportamentais das pessoas como forma de identificá-las unicamente, como impressões digitais; Botânica, evidências de origem vegetal; Zoologia, evidências de origem animal; Biologia Molecular, estudo da estrutura e função do material genético e seus produtos de expressão.

Como instrumentos de coleta de dados foram utilizados a observação direta durante 0 mini-curso e questionário no final deste, apontando quais conceitos foram assimilados, suas opiniões sobre as estratégias utilizadas, 
sobre todo o desenvolvimento do mini-curso e as contribuições que este proporcionou.

No desenvolvimento das aulas, a participação e os conhecimentos prévios dos alunos foram instrumentos que encaminharam a explicação teórico-dialogada, como também a exibição de um episódio do seriado "CSI", utilizado para apresentação do tema aos alunos. As diversas atividades realizadas foram de caráter educativo com várias dinâmicas $\mathrm{e}$ práticas, levantamento de hipóteses e discussões. As atividades práticas e lúdicas foram estratégias didáticas utilizadas para contextualizar o conteúdo e exemplificar situações reais, motivando a participação dos alunos nas discussões sobre o tema.

\section{RESULTADOS}

A análise do questionário respondido pelos alunos, no final do mini-curso, mostra que as dinâmicas e práticas utilizadas durante o desenvolvimento foram importantes para a compreensão dos conteúdos, como pode se observar nos argumentos dos alunos: "As explicações foram boas e as aulas dinâmicas", "Ponto positivo: experiências, desvendar casos, mesmo que sendo por uma atividade, interessante", "Bastante ênfase nas aulas práticas" (Alunos do Ensino Médio). A turma mostrou-se satisfeita em participar das dinâmicas propostas. Mesmo com termos técnicos mais difíceis de serem assimilados, houve a participação e curiosidade dos alunos sobre esses termos, "Divertido, interessante. A parte teórica foi um pouco complicada entender" (Aluno Ensino Médio).

Os gráficos 01 e 02 foram construídos com os dados coletados nos questionários. O gráfico 01 mostra como os participantes avaliaram o mini-curso, tendo como opções de resposta: ótimo; bom; regular ou ruim. O gráfico 02 demonstra qual a contribuição que o mini- curso proporcionou aos alunos em relação a aplicação no dia-a-dia, vestibular e complementação à disciplina de Biologia.

Como avalia o mini-curso que participou?

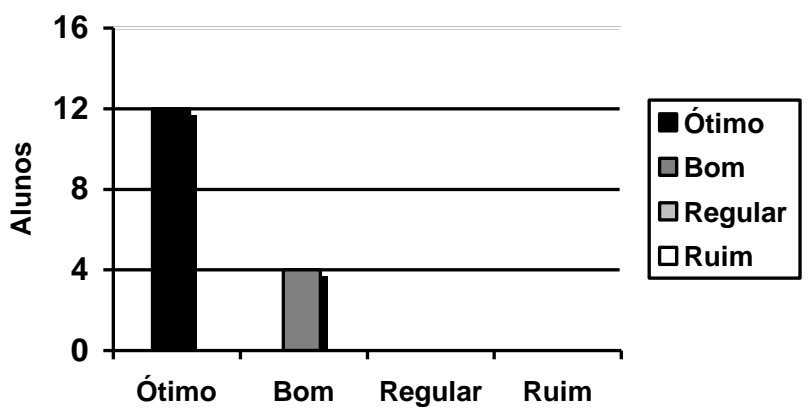

GRÁFICO 01 - Avaliação do mini-curso pelos alunos participantes

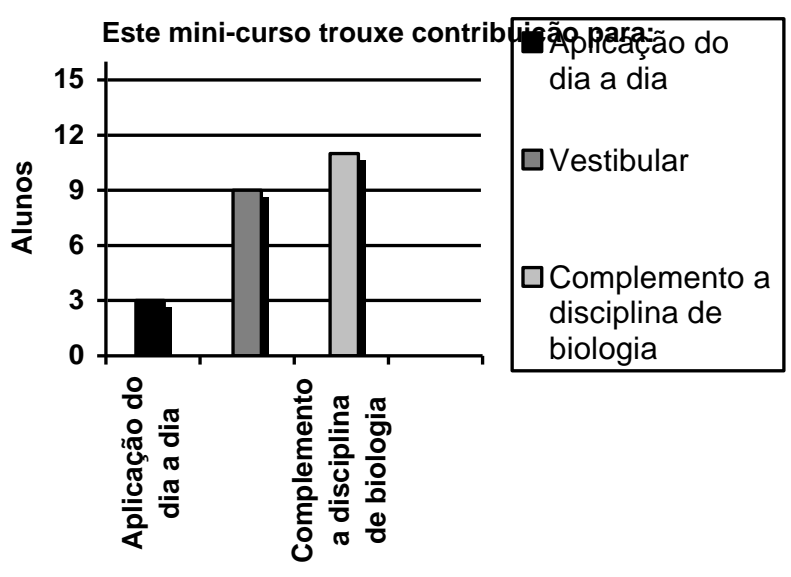

GRÁFICO 02 - Contribuição do mini-curso para
os alunos participantes

As respostas dos alunos nos questionários revelam o quanto houve aceitação do mini-curso e como esse tema pode contribuir em diferentes aspectos, como a revisão de conceitos importantes para a realização de provas de vestibular e a complementação da disciplina Biologia, ao conhecer a aplicação prática de conhecimentos científicos desta disciplina - fatores importantes na vida e desenvolvimento escolar dos alunos que, constantemente, questionam a utilidade de certos conteúdos. 


\section{DISCUSSÃO}

Segundo Moraes (2008), para que um novo conhecimento possa ser assimilado, é preciso que já existam nos conhecimentos prévios dos alunos, conceitos capazes de possibilitarem o estabelecimento de relações com o novo a ser apreendido. O diálogo é uma das alternativas mais indicadas para conhecer $\mathrm{e}$ explorar o conhecimento prévio dos alunos, contextualizando os temas abordados, realizando discussões onde os alunos possam expor suas opiniões, antes mesmo de discutir 0 conhecimento científico. A valorização do diálogo é uma das formas de envolvimento ativo dos alunos, processo especialmente reflexivo.

Durante as discussões no mini-curso percebeu-se o interesse dos alunos pelo tema e pelas situações reais simuladas durante a realização deste, possibilitando a compreensão do assunto. Os objetivos foram atingidos, pois, além de ampliar a visão dos alunos sobre a disciplina de Biologia, a interdisciplinaridade do tema e as estratégias utilizadas proporcionaram a interação entre os alunos, além da assimilação do conhecimento científico.

O ensino que se pretende é aquele que propicie condições para o desenvolvimento de habilidades, o que não se dá simplesmente por meio de exposições orais, mas de estratégias de ensino muito bem estruturadas e organizadas. Trabalhar com os alunos nesse sentido não se restringe a uma simples adequação de fatos descontextualizados da realidade, mas implica a redefinição de temas sociais próprios ao contexto nacional, local ou adaptados à problemática brasileira (PINHEIRO, 2007).

\section{CONCLUSÃO}

De acordo com os depoimentos dos alunos feitos oralmente e também escrito no questionário, a ampliação da visão dos alunos sobre as áreas da Biologia com o tema exposto no mini-curso de fato aconteceu. Como por exemplo: "Gostei muito do desenvolvimento do mini-curso, pois conheci um pouco de uma área até então desconhecida", "Achei muito bom o mini-curso, achei muito interessante, aprendi algumas coisas que não tinha nem idéia de como era feito". (Alunos Ensino Médio).

Abordar assuntos atuais, com estratégias diferenciadas, foi essencial para 0 bom desenvolvimento do mini-curso. Por meio da simulação do crime e aula prática houve maior interação dos alunos, facilitando a participação e assimilação dos conteúdos.

A aplicação de mini-curso e outras formas de estágio não convencional se mostra importante para a formação inicial docente, pois nesta modalidade, a quantidade de alunos é menor, proporcionando maior contato e discussão entre aluno-professor, e ainda há a chance de aplicar diversas dinâmicas durante a aula tornando-a mais interessante, contextualizada e prática, além de ser possível abordar tanto temas de vestibular como temas do cotidiano do aluno, atraindo a sua curiosidade para a disciplina com temas não abordados no currículo escolar, mas que também colaboram na construção do conhecimento cientifico.

\section{REFERÊNCIAS}

BARBOSA, L. M. S. Temas Transversais: como utilizá-los na prática educativa? Curitiba: Ibpex., 2007.

BARALDI, A. M. A utilização da Técnica de identificação genética: panorama da realidade dos serviços oficiais de identificação brasileiros e a importância do cirurgião-dentista na equipe forense. 2008. Dissertação (Mestrado em Ciências odontológicas) - Faculdade de Odontologia da Universidade de São Paulo, São Paulo.

BIMBATO, E. P.; ANTIGO, M. R.; GIANOTTO, D. É. P. Minicurso, uma modalidade de ensinoaprendizagem -"conhecendo o corpo humano pelos cinco sentidos: interação e aprendizado". In: XI ENCONTRO MARINGAENSE DE BIOLOGIA. 
11, SEMANA DA BIOLOGIA. 24., Maringá Anais... Maringá, 2009.

CALAZANS, C. H.; CALAZANS, S. M. Ciência forense: das origens à ciência forense computacional. Laboratório de sistemas integrados. São Paulo: Escola politécnica. Universidade de São Paulo, 2010.

MACHADO, H.; NUNES J. A. Usos e representações da ciência e de novas tecnologias nos tribunais e reconfigurações da cidadania. In: Congresso da Associação Portuguesa de Sociologia. 5., Braga. Anais... Braga, 2004.

MORAES, R. (Org.). Construtivismo e ensino de Ciências: reflexões epistemológicas e metodológicas. 3.ed. Porto Alegre: EDIPUCRS, 2008.

PINHEIRO, N. A. M.; SILVEIRA, R. M. C. F.; BAZZO, W. A. Ciência, tecnologia e sociedade: a relevância do enfoque CTS para o contexto do Ensino Médio. Ciência \& Educação, v. 13, n. 1, 2007. p. 71-84.

SILVA L. A. F.; PASSOS N. S. DNA Forense: coleta de amostras biológicas em locais de crime para estudo do NDA. Maceió: Edufal, 2006. 